\title{
Tumour characteristics and survivorship in a cohort of breast cancer: the MCC-Spain study
}

\author{
Inés Gómez-Acebo ${ }^{1,2,25}$. Trinidad Dierssen-Sotos ${ }^{1,2} \cdot$ Camilo Palazuelos-Calderón $^{2} \cdot$ Beatriz Pérez-Gómez ${ }^{1,3}$. \\ Pilar Amiano ${ }^{5}$. Marcela Guevara ${ }^{1,6,7}$. Antonio J. Molina ${ }^{8} \cdot$ Laia Domingo $^{9,10} \cdot$ María Fernández-Ortiz $^{2}$. \\ Victor Moreno $0^{1,11,12,13}$. Juan Alguacil ${ }^{1,14}$. Guillermo Fernández-Tardón ${ }^{15}$. Josefa Ibáñez ${ }^{16,17}$. \\ Rafael Marcos-Gragera ${ }^{1,18,19}$ - Marian Diaz-Santos ${ }^{20} \cdot$ M. Henar Alonso ${ }^{1,11,12,13}$. Jessica Alonso-Molero ${ }^{2}$. \\ Gemma Castaño-Vinyals ${ }^{1,21,22,23} \cdot$ Andrés García Palomo ${ }^{24} \cdot$ Eva Ardanaz $^{1,6,7} \cdot$ Amaia Molinuevo $^{5}$. Nuria Aragonés ${ }^{1,4}$. \\ Manolis Kogevinas ${ }^{1,21,22,23} \cdot$ Marina Pollán ${ }^{1,3}$. Javier Llorca ${ }^{1,2}$
}

Received: 13 December 2019 / Accepted: 18 March 2020 / Published online: 30 April 2020

(c) The Author(s) 2020

\begin{abstract}
Purpose The objective of this study is to analyse the relative survival with breast cancer in women diagnosed after new treatments were generalised and to ascertain the current effect that tumour characteristics such as grade, stage or subtype have on survival as well as the new AJCC-pathological prognostic score.

Methods The breast cancer MCC-Spain follow-up study is a prospective cohort study of 1685 incident breast cancer cases. Women between 20 and 85 years old were recruited between the years 2008 and 2013 in 18 hospitals located in 10 Spanish provinces and they have been followed until 2017/2018. Relative survival was estimated after 3, 5 and 8 years of follow-up using Ederer II method. In addition, Weibull regression adjusted by age, hospital, grade and stage was used to investigate prognosis factors.

Results Among components of TNM staging system, tumour size greater than $50 \mathrm{~mm}$ (i.e. T3 or T4) more than doubled the risk of dying, while N3 nodal involvement and presence of metastasis had a huge effect on mortality. The AJCC pathological prognostic score strongly correlated with survival; thus, hazard ratios increased as the score rose, being 2.31, 4.00, 4.94, 7.92, 2.26, 14.9 and 58.9 for scores IB, IIA, IIB, IIIA, IIIB, IIIC and IV, respectively.

Conclusion Both TNM staging and histological/molecular biomarkers are associated with overall survival in Spanish women with breast cancer; when both are combined in the AJCC pathological prognosis score, the prognostic value improved with risk indices that increased rapidly as the pathological prognosis score increased
\end{abstract}

Keywords Cohort $\cdot$ Epidemiology $\cdot$ Breast cancer $\cdot$ Relative survival $\cdot$ MCC-spain

\begin{tabular}{ll}
\multicolumn{2}{l}{ Abbreviations } \\
BC & Breast cancer \\
BMI & Body mass index \\
MCC-Spain & Multicase-control Spain \\
OR & Odds ratios \\
RRR & Relative risk ratio \\
CI & Confidence intervals
\end{tabular}

Electronic supplementary material The online version of this article (https://doi.org/10.1007/s10549-020-05600-x) contains supplementary material, which is available to authorised users.

Inés Gómez-Acebo

ines.gomez@unican.es

Extended author information available on the last page of the article

\section{Introduction}

Breast cancer (BC) is the most frequent cancer and the fourth cause of death by cancer in women in developed countries [1]. Rates of survival with breast cancer have increased significantly all over the world in the past decades [2]. In Spain, it has been estimated that 32,825 new BC cases were diagnosed in 2018, with an incidence rate (Age-standardised [World]) of 75.4 cases per 100,000 women-years [3]. Main factors associated with prognosis in breast cancer are stage (enclosing tumour size and local infiltration, lymph nodes and metastasis), tumour grade of differentiation, histological type and presence/absence of hormone and Her2/neu receptors [2]. 
Although paclitaxel has been available since 1993, breast cancer treatment has considerably improved from 1995 onwards as conservative surgery has become widely performed. Systemic therapy has switched from CMF (cyclophosphamide, methotrexate and 5-fluorouracil) to regimens containing anthracycline [4], routine searches for oestrogen and progesterone receptors has allowed for the introduction of tamoxifen, as well as identification of tumours positive to Her $2 /$ neu has enabled targeted therapy with trastuzumab [5], which was authorised in the European Union on August 28,2000 . In this regard, identification of intrinsic subtypes (i.e. luminal A, luminal B, Her2-positive and basal-like) has allowed for agreement in general recommendations for firstline therapy in early-stage breast cancer [6]. Survival has thus enhanced and 5-year survival is now around 85\% [7-9]. In spite of the improvement in systemic therapy, tumour stage remains a key prognosis factor in breast cancer patients [10], which reinforces the relevance of early diagnosis. The American Joint Committee for Cancer (AJCC) has recently suggested a pathological prognostic score combining tumour stage, grade and hormonal/Her2 receptors [11], which has been proved effective as survival predictor $[12,13]$.

Studies carried out in population-based cancer registries covering $17 \%$ of the Spanish population reported that women with BC diagnosed in Spain had 86.0\% 5-year age-adjusted relative survival if diagnosed between 1995 and 1999 [7, 14] with no improvements for women diagnosed from 2000 to 2007 [7]. That study, however, included women diagnosed well before the extension of anthracycline-based chemotherapy and the introduction of endocrine therapy with tamoxifen and anti-Her 2 treatment with trastuzumab. The main goal in this study is to analyse the relative survival with $\mathrm{BC}$ in women diagnosed in 2008-2013 - after new treatments were generalised-and to ascertain the current effect that tumour characteristics such as grade, stage or subtype have on survival as well as the new AJCC-pathological prognostic score.

\section{Methods}

\section{Setting and patients}

The breast cancer MCC-Spain follow-up study is a prospective cohort study of incident breast cancer cases diagnosed between 2008 and 2013 in 18 hospitals located in 10 Spanish provinces (Asturias, Barcelona, Cantabria, Girona, Gipuzkoa, Huelva, León, Madrid, Navarra and Valencia). 1738 women between 20 and 85 years old with newly diagnosed primary breast cancer were recruited in the context of a case-control study. The identification of incident cases was carried out by active search through periodic visits to the relevant hospital departments (i.e. gynaecology, oncology, general surgery, radiotherapy and pathology departments). All the cases that were included had histological confirmation and included all the malignant BC (International Classification of Diseases 10th Revision (ICD-10) [15] code C50) and frequent breast cancers in situ (ICD-10: D05.1, D05.7), without a malignant history of BC, diagnosed between 2008 and 2013 in the selected hospitals. Patients were residing in the catchment areas of hospitals for at least 6 months before recruitment. A detailed description of methods and sample characteristics has been published elsewhere $[16,17]$ and then, 98\% recruited patients have been followed until $2017 / 2018(N=1685)$. Only patients signing an informed consent were recruited; the informed consent also asked them for their permission for later consulting their medical records during the follow-up.

\section{Information obtained at recruitment}

When the patients were recruited, medical records were reviewed in order to gather information on age, date of diagnosis, tumour characteristics, including tumour size, lymph nodes, presence of metastases, grade of differentiation. Furthermore, oestrogen (ER), progesterone (PgR) and human epidermal growth factor receptor 2 (HER2) status were assessed and then classified as positive $(+)$, negative (-) and unknown. Specifically, ER and PgR were considered positive if $1 \%$ or more of neoplastic cells showed nuclear immunohistochemical (IHC) staining. HER2 was considered positive (overexpressed) if graded $3+$ on IHC performed, and all other grades ( 0 to $2+$ ) were considered negative unless fluorescence in situ hybridization of $2+$ cases confirmed increased gene copy number. Molecular subtypes of breast carcinoma is classified into luminal A (ER + and / or PR +, HER2-, Ki-67<14\%), luminal B (ER + and / or $\mathrm{PR}+$, HER2-, or ER + and / or PR +, HER2-, Ki-67 $\geq 14 \%$ ), HER2 + (ER-, PR-, HER2 +) and basal-like or triple negative is a tumour which does not meet any pathologic criteria for positivity of oestrogen receptor, progesterone receptor, or ERBB2 (ER-, PR- and HER2-) [6]. Tumour stage was based on the AJCC standards [18]. Tumour size was classified as $\mathrm{T} 1: \leq 2 \mathrm{~cm}, \mathrm{~T} 2:>2 \mathrm{~cm}$ and $\leq 5 \mathrm{~cm}, \mathrm{~T} 3:>5 \mathrm{~cm}, \mathrm{~T} 4:$ any size with direct extension to chest wall and/or skin; lymph node involvement was classified as N0: no pathologically proven positive lymph nodes, N1: 1-3 positive nodes, N2: 4-9 positive nodes, N3: $\geq 10$ positive nodes. Tumour grade was categorised as I: well differentiated, II: moderately differentiated, III: poorly differentiated, according to the modified Bloom and Richardson grading system [19]; when Bloom and Richardson grade was unavailable, other similar classifications were used as it has been proved they are highly reliable [20]. First-line therapy was also recorded, including type of surgery (conservative or mastectomy), margins (free or invaded), chemotherapy regime, radiotherapy, 
endocrine therapy, Her2-targeted therapy; for all systemic therapies, whether they were adjuvant or neoadjuvant was also recorded.

\section{Follow-up}

In 2017 and 2018, medical records were reviewed to obtain the last date the patient was attended to in $t$ the health system and to ascertain current patient's vital status. For patients that had not have been at hospital in the 3 months before their medical record review, the National Death Index (Índice Nacional de Defunciones) was consulted [21]. This index is a database recording date of death for all people who have died in Spain; it is hosted on the Ministry of Health web page and can only be accessed with specific authorisation for research purposes. Last date of search in the National Death Index was in December 2018.

\section{Statistical analysis}

Deaths by any cause were considered events and patients alive in their last contact with hospital and not included in the National Death Index were considered censored. Time of follow-up was considered as the time from diagnosis to death or to the last contact in hospital in alive patients. Relative survival, defined as the ratio of the observed survival in our study population and the expected survival in general population Spanish women with the same age as cases in the year of diagnosis, was estimated using Ederer II method [22]; for this purpose, age-specific mortality rates from 2007 to 2018 obtained from the Spanish National Institute for Statistics (INE) were used as reference. 3-, 5- and 8-year survival Kaplan-Meier estimates were obtained. Weibull regression adjusting by age, hospital, grade and stage was used to investigate prognosis factors; its results are displayed as hazard ratios with their $95 \%$ confidence intervals. Groups that included less than 25 people were excluded from this analysis. Stata 14/SE package was used in the analyses.

\section{Results}

\section{Characteristics of patients}

We followed 1685 women out of 1738 breast cancer patients (98\%), who had primary breast cancer between 2007 and 2013. Patient-years of follow-up were 10,931 person-years. The maximum period for breast cancer follow-up was nine and a half years (from 13th July 2007 to 22nd March 2018) and 206 patients died in the follow-up; 5-year survival was $90.7 \%$.
The mean age at diagnosis was $56.5 \pm 12.6$-year-old and $65 \%$ were postmenopausal. Other main characteristics of the patients are shown in supplementary Table 1.

\section{Tumour characteristics}

Regarding the characteristics of the tumours, the most usual histological type was ductal (75.7\%), followed by lobular (6.5\%). About half of cancers were T1 (52\%) and lymph node negatives $(52 \%)$. Only 42 women $(2.5 \%)$ had metastasis at the time of diagnosis.

Concerning intrinsic subtypes, 997 (59.2\%) could be classified as luminal A-like, $331(19.6 \%)$ as luminal B-like, 81 (4.8\%) as Her2 (non-luminal)-like and 130 (7.7\%) as basallike. Grade of differentiation could not be obtained from medical records in 481 patients (28.5\%). Almost $31 \%$ of the cancers were moderately differentiated while poorly differentiated accounted for about $21 \%$ cancers. Hormone receptor status was available for most cases; $83 \%$ were oestrogen receptor positive, $73 \%$ progesterone positive and $17.4 \%$ were Her2 positive (Table 1).

\section{Relative survival}

5-year relative survival with breast cancer was 93\% (95\% CI 92 -94) (Fig. 1a). Table 1 shows 3-, 5- and 8-year relative survival according to tumour characteristics. Women diagnosed in stage I had the same survival probability than women with the same age without breast cancer (i.e. $100 \%$ relative survival) even after 8 years of follow-up. At the same time, relative survival decreased with follow-up time in women diagnosed in more advanced stages: 3-, 5- and 8-year relative survival were $98 \%, 95 \%$ and $93 \%$ for breast cancer diagnosed in stage II, 94\%, $88 \%$ and $81 \%$ in women diagnosed in staged III and 63\%, $40 \%$ and $24 \%$ in those diagnosed in staged IV (Table 1 and Fig. 1b). Relative survival also decreased as grading got less differentiated [8-year relative survival: $99 \%$ in well differentiated tumours, $93 \%$ in moderately differentiated and $88 \%$ in poorly differentiated (Table 1 and Fig. 1c)]. Relative survival after 8 years of follow-up was $94 \%$ for luminal A-like breast cancers, $88 \%$ for luminal B-like, $82 \%$ for Her2 non-luminal) and $74 \%$ for basal-like cancers (Table 1 and Fig. 1d).

\section{Prognostic factors on overall mortality}

Age, hospital, stage and grade-adjusted hazard ratios on association between survival and tumour characteristics and first-line treatment are displayed in Table 2. Age, premenopausal status, tumour size, nodal infiltration and presence of metastasis were significantly associated with overall mortality. Hazard ratios increased with tumour stage, being 1 (reference) for T1 and $1.62(1.04-2.52)$ 
Table 1 Relative survival probability 3, 5 and 8 years after breast cancer diagnosis according to tumour characteristics

\begin{tabular}{|c|c|c|c|c|c|}
\hline Variable & Category & $N(\%)$ & $\begin{array}{l}\text { 3-year } \\
\text { Survival }(95 \% \mathrm{CI})\end{array}$ & $\begin{array}{l}\text { 5-year } \\
\text { Survival }(95 \% \mathrm{CI})\end{array}$ & $\begin{array}{l}\text { 8-year } \\
\text { Survival }(95 \% \text { CI })\end{array}$ \\
\hline \multirow[t]{3}{*}{ Histology } & Ductal & $1276(75.73)$ & 97 (95-98) & 93 (92-95) & $91(88-93)$ \\
\hline & Lobular & $110(6.53)$ & 95 (88-98) & 89 (80-94) & 87 (76-94) \\
\hline & Other & 299 (17.74) & $100(98-101)$ & 97 (94-99) & $97(92-100)$ \\
\hline \multirow[t]{6}{*}{ Tumour size } & $\mathrm{T} 1$ & $876(51.99)$ & $100(99-101)$ & 98 (97-99) & 97 (95-99) \\
\hline & $\mathrm{T} 2$ & $424(25.16)$ & $96(93-98)$ & $91(87-94)$ & 87 (81-91) \\
\hline & $\mathrm{T} 3$ & $73(4.33)$ & 88 (77-94) & $75(63-85)$ & $71(58-81)$ \\
\hline & $\mathrm{T} 4$ & $39(2.31)$ & $74(56-86)$ & $59(41-74)$ & $59(40-75)$ \\
\hline & Tis & $109(6.47)$ & $101(101-101)$ & $102(102-102)$ & $100(91-103)$ \\
\hline & Missing & $141(8.37)$ & $93(86-97)$ & 87 (80-93) & 81 (69-90) \\
\hline \multirow[t]{5}{*}{ Node infiltration } & N0 & 877 (52.05) & $100(99-100)$ & 97 (95-99) & $98(96-100)$ \\
\hline & N1 & $441(26.17)$ & 97 (95-99) & $94(91-96)$ & $90(85-94)$ \\
\hline & $\mathrm{N} 2$ & $142(8.43)$ & 93 (86-97) & $85(77-91)$ & $78(68-86)$ \\
\hline & $\mathrm{N} 3$ & $49(2.91)$ & $81(67-91)$ & 77 (61-87) & $61(40-78)$ \\
\hline & Missing & $176(10.45)$ & $92(86-96)$ & $88(81-93)$ & 79 (69-87) \\
\hline \multirow[t]{5}{*}{ Tumour stage } & 0 & $112(6.65)$ & $100(95-101)$ & $101(96-102)$ & $98(89-102)$ \\
\hline & I & $594(35.25)$ & $101(99-101)$ & $99(97-101)$ & $100(97-102)$ \\
\hline & II & 498 (29.55) & $98(96-100)$ & 95 (92-97) & $93(88-96)$ \\
\hline & III & $187(11.10)$ & 94 (89-97) & $88(82-93)$ & $81(72-88)$ \\
\hline & IV & $42(2.49)$ & $63(46-77)$ & $40(24-55)$ & $24(11-40)$ \\
\hline \multirow[t]{2}{*}{ Oestrogen receptor } & Positive & $1398(82.97)$ & $99(98-100)$ & $96(94-97)$ & $93(91-95)$ \\
\hline & Negative & $244(14.48)$ & $86(81-90)$ & $81(75-86)$ & $80(73-85)$ \\
\hline \multirow[t]{2}{*}{ Progesterone receptor } & Positive & $1237(73.41)$ & $100(98-100)$ & $97(95-98)$ & $95(92-97)$ \\
\hline & Negative & $401(23.80)$ & $90(86-93)$ & $85(80-88)$ & $81(76-85)$ \\
\hline \multirow[t]{2}{*}{ Her2 } & Negative & $1250(74.18)$ & $97(96-98)$ & $93(92-95)$ & $91(88-93)$ \\
\hline & Positive & $294(17.45)$ & 97 (94-99) & $93(89-96)$ & $89(84-93)$ \\
\hline \multirow[t]{5}{*}{ Intrinsic subtype } & Luminal A & 997 (59.17) & $100(98-100)$ & $96(94-98)$ & $94(92-97)$ \\
\hline & Luminal B & $331(19.64)$ & 97 (95-99) & $94(90-97)$ & $88(83-93)$ \\
\hline & Her2 & $81(4.81)$ & $94(86-99)$ & $87(76-93)$ & $82(70-91)$ \\
\hline & Basal-like & $130(7.72)$ & $78(70-85)$ & $74(65-81)$ & $74(64-82)$ \\
\hline & Luminal ONI & $91(5.40)$ & $100(94-101)$ & $101(95-102)$ & $101(92-104)$ \\
\hline \multirow[t]{4}{*}{ Grade } & I: Well differentiated & $329(19.53)$ & $100(98-101)$ & $99(96-101)$ & $99(95-102)$ \\
\hline & II: Moderately differentiated & $520(30.86)$ & $100(98-101)$ & $95(92-97)$ & $93(89-96)$ \\
\hline & III: Poorly differentiated & $355(21.07)$ & $93(89-95)$ & $90(86-94)$ & $88(83-92)$ \\
\hline & Missing & $481(28.55)$ & $96(93-98)$ & $91(88-94)$ & $88(83-91)$ \\
\hline
\end{tabular}

ONI Otherwise non-identified, Luminal ONI hormonal receptors positive, Her2 missing, Non-luminal ONI hormonal receptors negative, Her2 missing

and $2.04(1.13-3.68)$ for $\mathrm{T} 2, \mathrm{~T} 3$, respectively. Breast cancers negative for oestrogen or progesterone receptors behaved worse than their opposite. Luminal A- like and luminal B-like tumours had similar prognosis; hazard for Her2 (non-luminal) cancers were 50\% higher than for luminal A-like (hazard ratio $=1.50 ; 95 \%$ CI $0.87-2.59$ ), and basal-like tumour's hazard was three times that of luminal A-like (hazard ratio $=3.50 ; 95 \%$ CI $2.31-5.30$ ). Grading showed a dose-response association with mortality, with hazard ratios 1 (reference) for well differentiated cancers, $1.48(0.86-2.54)$ for moderately differentiated and $2.42(1.41-4.17)$ for poorly differentiated. To further explore whether intrinsic subtype adds prognosis value to tumour stage, we studied the effect of stage by stratifying for intrinsic subtype; results in Fig. 2a show that higher stages had higher hazard ratios, whatever the intrinsic subtype. However, when stratifying the effect of intrinsic subtype for tumour stage, we found that intrinsic subtype had no effect at all in patients in stage I, while Her2 (nonluminal) and basal-like tumours had worse prognosis than luminal-like tumours in patients with stage II and, especially, stages III and IV (Fig. 2b). 
(a)

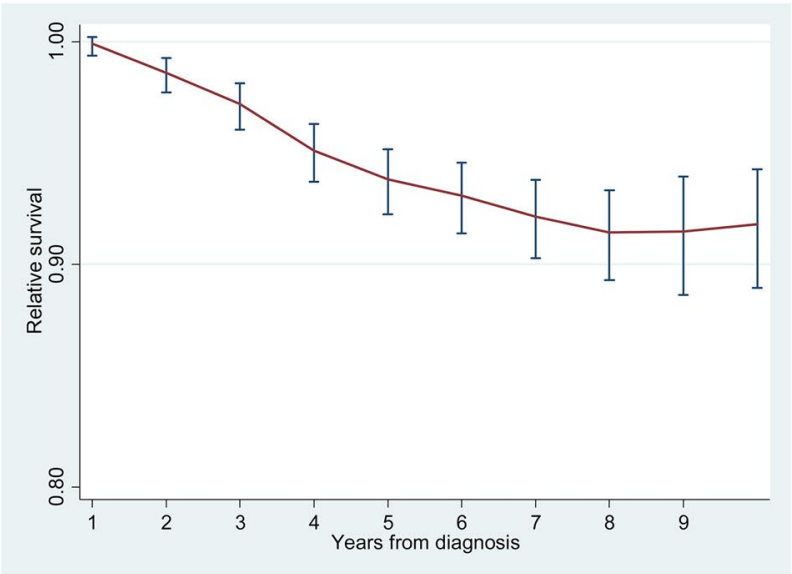

(c)

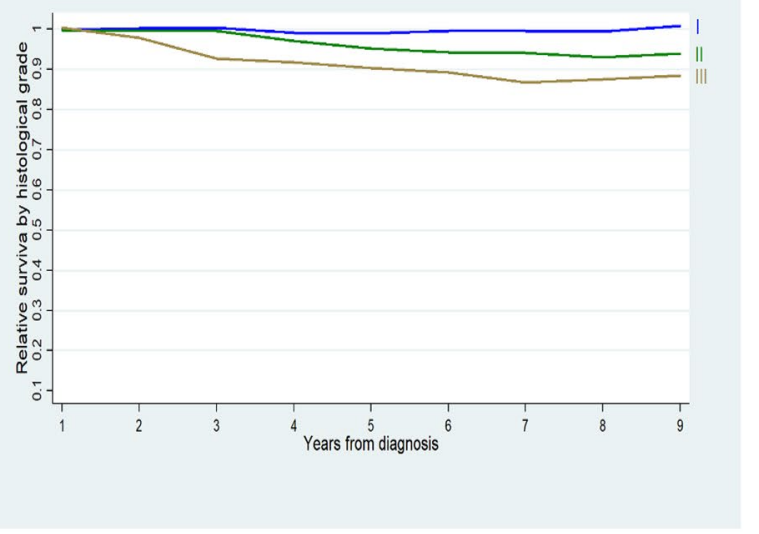

(b)

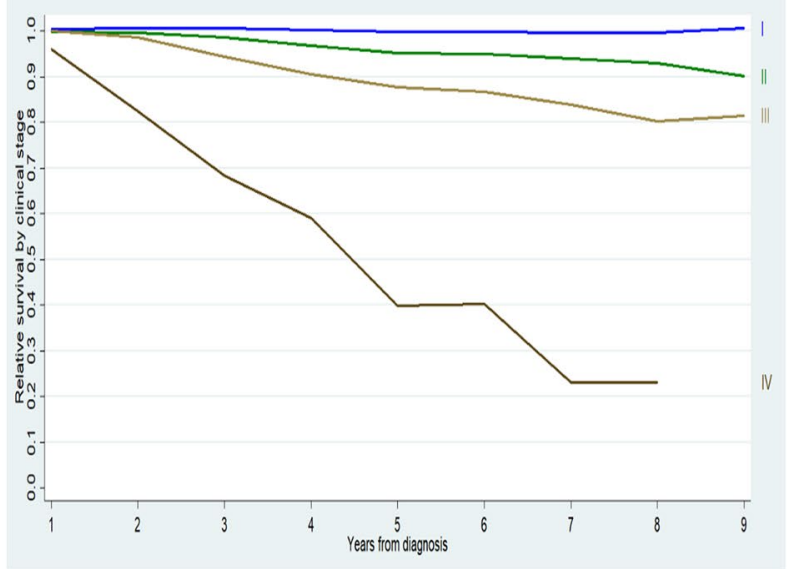

(d)

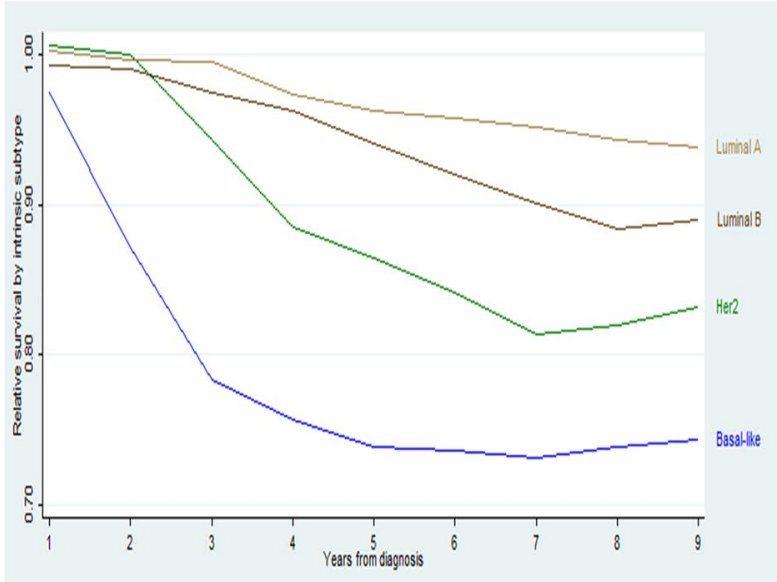

Fig. 1 Relative survival in Spanish women with breast cancer: a Overall survival, b survival according to TNM staging, $\mathbf{c}$ survival according to grading, $\mathbf{d}$ survival according to intrinsic subtype

\section{Pathologic prognostic score in women without neoadjuvant therapy}

Figure 3 displays the association between the AJCC- Pathologic Prognostic Score and overall survival in women without neoadjuvant therapy. Hazard ratios stepped up as the score rose, being 2.31, 4.00, 4.94, 7.92, 2.26, 14.9 and 58.9 for scores IB, IIA, IIB, IIIA, IIIB, IIIC and IV, respectively. These results are somewhat limited because of their wide confidence intervals. This information appears stratified by menopausal status in supplementary material, where hazard ratios increased faster in premenopausal women (Supplementary Table 2).

\section{First-line treatment for patients}

Table 3 shows the characteristics of the treatment. Conservative surgery was performed in $1231(73.1 \%)$ patients and mastectomy in the remaining 454 (26.9\%). Surgical margins were negative in $66 \%$ patients. Radiotherapy was used in 1158 women (68.7\%), while adjuvant or neoadjuvant chemotherapy was administered to $50.13 \%$ patients. Adjuvant or neoadjuvant hormone therapy was used in 1023 women (60.7\%), immunotherapy in $11.1 \%$ and Her2-targeted therapy in 152 patients (9.0\%).

Hazard ratios on association between survival and first-line treatment are displayed in Table 4. Type of surgery (mastectomy/conservative surgery) and surgical margins were not associated with survival. Among systemic treatments, adjuvant therapy (whether chemo-, radio- or hormone-therapy) was associated with lower mortality and both neoadjuvant and palliative treatment were associated with worse prognosis (Table 4). 
Table 2 Characteristics of the tumour and their association with survival

\begin{tabular}{|c|c|c|c|c|}
\hline Variable & Category & $N(\%)$ & Hazard ratio $(95 \% \mathrm{CI})^{*}$ & $p$ \\
\hline \multirow[t]{3}{*}{ Histology } & Ductal & $1276(75.73)$ & 1 (ref) & \\
\hline & Lobular & $110(6.53)$ & $1.12(0.68$ to 1.83$)$ & 0.666 \\
\hline & Other & $299(17.74)$ & $0.44(0.26$ to 0.72$)$ & 0.001 \\
\hline \multirow[t]{6}{*}{ Tumour size } & $\mathrm{T} 1$ & $876(51.99)$ & 1 (ref) & \\
\hline & $\mathrm{T} 2$ & $424(25.16)$ & 1.62 (1.04 to 2.52$)$ & 0.031 \\
\hline & $\mathrm{T} 3$ & $73(4.33)$ & 2.04 (1.13 to 3.68$)$ & 0.018 \\
\hline & $\mathrm{T} 4$ & $39(2.31)$ & $1.96(0.98$ to 3.91$)$ & 0.056 \\
\hline & Tis & $109(6.47)$ & $0.14(0.02$ to 0.91$)$ & 0.04 \\
\hline & Missing & $141(8.37)$ & $1.12(0.61$ to 2.06$)$ & 0.718 \\
\hline \multirow[t]{5}{*}{ Node infiltration } & No & $877(52.05)$ & 1 (ref) & \\
\hline & N1 & $441(26.17)$ & $1.16(0.76$ to 1.78$)$ & 0.481 \\
\hline & $\mathrm{N} 2$ & $142(8.43)$ & $1.17(0.58$ to 2.36$)$ & 0.651 \\
\hline & N3 & $49(2.91)$ & $1.73(0.81$ to 3.72$)$ & 0.158 \\
\hline & Missing & $176(10.45)$ & $1.15(0.65$ to 2.03$)$ & 0.641 \\
\hline \multirow[t]{5}{*}{ Tumour stage } & 0 & $112(6.65)$ & $0.68(0.26$ to 1.81$)$ & 0.444 \\
\hline & I & $594(35.25)$ & 1 (ref) & \\
\hline & II & $498(29.55)$ & $2.30(1.46$ to 3.61$)$ & $>0.001$ \\
\hline & III & $187(11.10)$ & 4.23 (2.60 to 6.88$)$ & $>0.001$ \\
\hline & IV & $42(2.49)$ & 29.5 (16.9 to 51.6$)$ & $>0.001$ \\
\hline \multirow[t]{2}{*}{ Oestrogen receptor } & Positive & $1398(82.97)$ & 1 (ref) & \\
\hline & Negative & $244(14.48)$ & 2.31 (1.65 to 3.23$)$ & $>0.001$ \\
\hline \multirow[t]{2}{*}{ Progesterone receptor } & Positive & $1237(73.41)$ & 1 (ref) & \\
\hline & Negative & $401(23.80)$ & 2.13 (1.58 to 2.87$)$ & $>0.001$ \\
\hline \multirow[t]{2}{*}{ Her2 } & Negative & $1250(74.18)$ & $1(\mathrm{ref})$ & \\
\hline & Positive & $294(17.45)$ & $0.79(0.55$ to 1.14$)$ & 0.209 \\
\hline \multirow[t]{5}{*}{ Intrinsic subtype } & Luminal A & $997(59.17)$ & 1 (ref) & \\
\hline & Luminal B & $331(19.64)$ & $1.16(0.81$ to 1.66$)$ & 0.429 \\
\hline & Her2 & $81(4.81)$ & $1.50(0.87$ to 2.59$)$ & 0.143 \\
\hline & Basal-like & $130(7.72)$ & $3.50(2.31$ to 5.30$)$ & $>0.001$ \\
\hline & Luminal ONI & $91(5.40)$ & $0.20(0.05$ to 0.82$)$ & 0.026 \\
\hline \multirow[t]{4}{*}{ Grade } & I: Well differentiated & $329(19.53)$ & 1 (ref) & \\
\hline & II: Moderately differentiated & $520(30.86)$ & $1.48(0.86$ to 2.54$)$ & 0.157 \\
\hline & III: Bad differentiated & $355(21.07)$ & $2.42(1.41$ to 4.17$)$ & 0.001 \\
\hline & missing & $481(28.55)$ & $2.31(1.27$ to 4.18$)$ & 0.006 \\
\hline
\end{tabular}

Hazard ratios and 95\% confidence intervals estimated via Weibull regression

*Hazard ratios adjusted for age, hospital, stage and grade

$O N I$ otherwise not identified

\section{Discussion}

In spite of recent improvements in breast cancer systemic therapy, our results confirm that tumour stage and grading are major prognosis factors regarding overall survival with breast cancer. Among components of TNM staging system, tumour size greater than $50 \mathrm{~mm}$ (i.e. T3 or T4) more than doubled the risk of dying, while N3 nodal involvement and presence of metastasis had a huge effect on mortality. The pathological prognostic score suggested by the AJCC in 2017 combining anatomic characteristics (i.e. TNM staging) with biological characteristics (i.e. grading and hormonal/Her2 receptors) strongly correlated with survival.

TNM staging has largely been the main factor regarding survival with breast cancer, which led the AJCC to suggest its Anatomic Stage Groups [11]. Our results on TNM components are consistent with recent studies still proving that TNM classification is a main contributor to survival [10, 23-25]. For instance, a large study with data from Netherlands Cancer Registry reported hazard ratios over 2.5 for $\mathrm{T} 3$ or T4 tumours and 4.0 for $\mathrm{N} 3$ tumours in women diagnosed between 2006 and 2012. These hazard ratios were similar to those obtained in the same registry for women diagnosed 
(a)

TNM STAGE

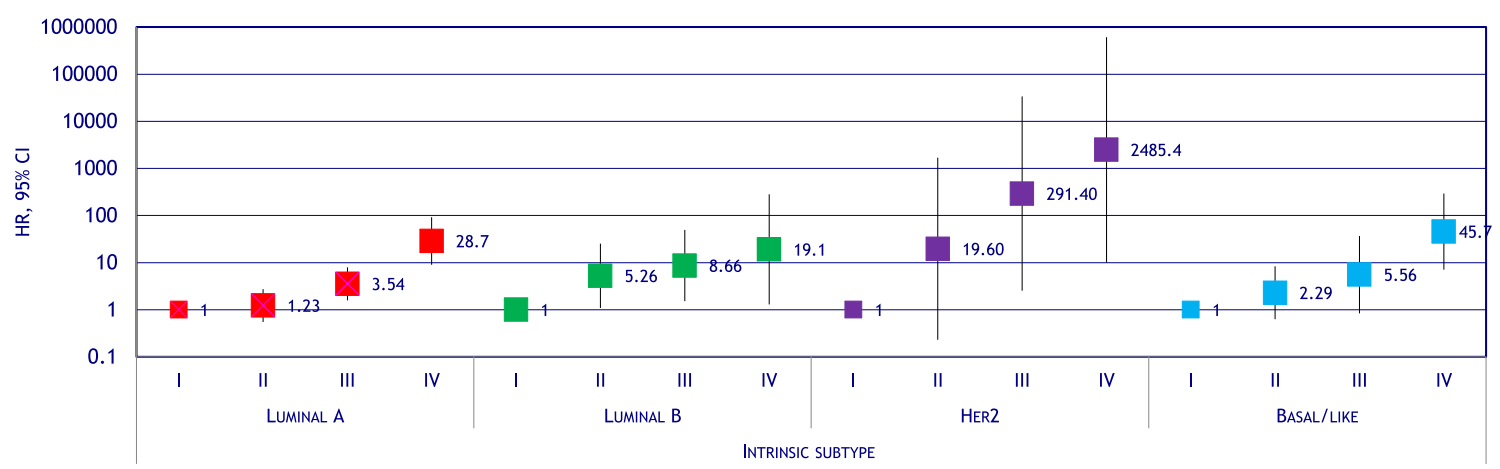

(b)

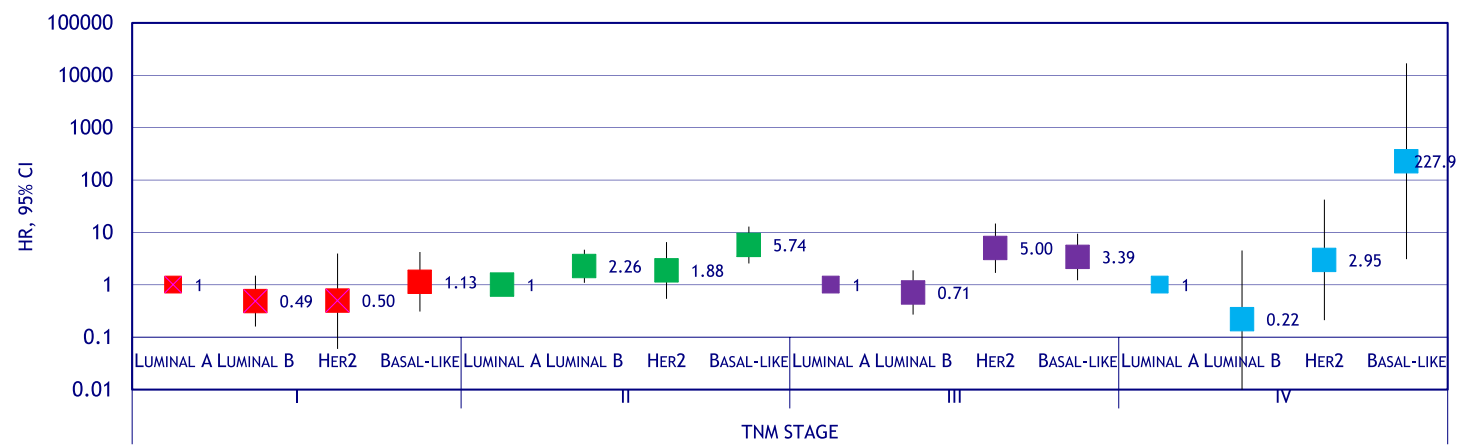

Fig. 2 Hazard ratios for overall survival showing the interaction between TNM stage and intrinsic subtype. a Hazard ratios for TNM stage stratified by intrinsic subtype, $\mathbf{b}$ hazard ratios for intrinsic subtype stratified by TNM stage

Fig. 3 Kaplan-Meier survival estimates according to the AJCC pathological prognostic score

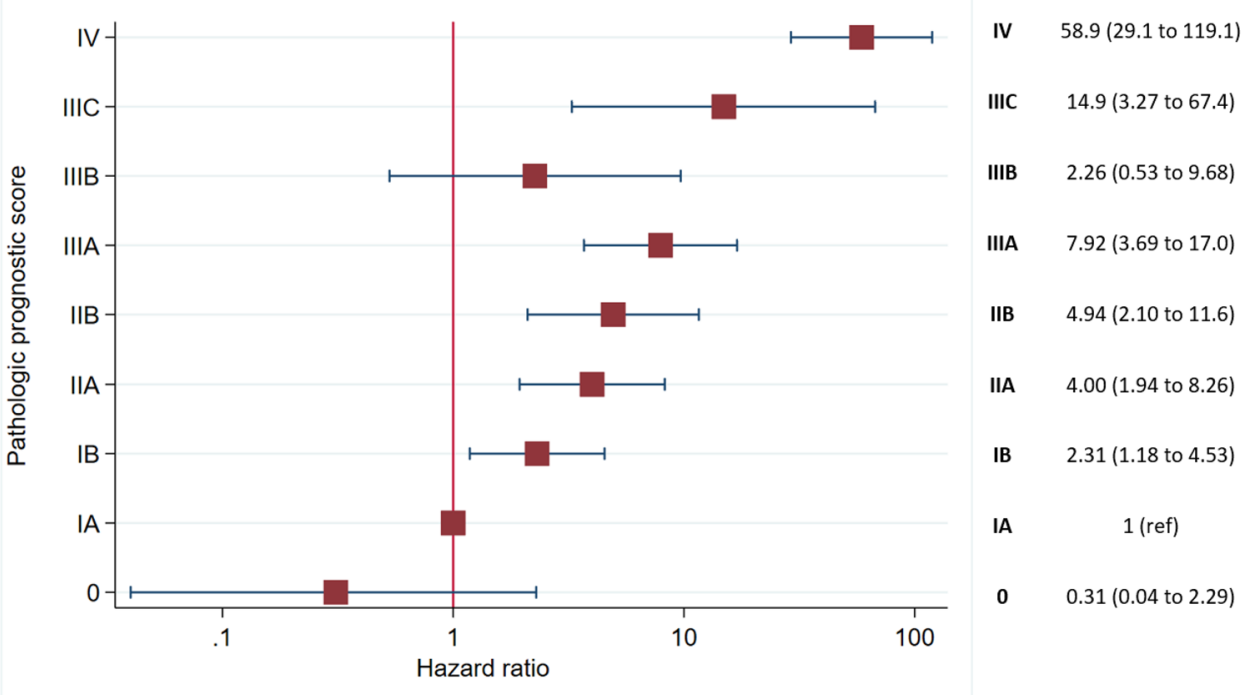

*HR adjusted for age at diagnosis and hospital 
Table 3 First-line treatment and relative survival probability 3, 5 and 8 years after diagnosis

\begin{tabular}{|c|c|c|c|c|c|}
\hline Variable & Category & $N(\%)$ & $\begin{array}{l}\text { 3-year } \\
\text { Survival }(95 \% \text { CI })\end{array}$ & $\begin{array}{l}\text { 5-year } \\
\text { Survival }(95 \% \text { CI })\end{array}$ & $\begin{array}{l}8 \text {-year } \\
\text { Survival }(95 \% \text { CI) }\end{array}$ \\
\hline \multirow[t]{2}{*}{ Surgery } & Conservative & $1231(73.06)$ & $98(97-99)$ & 95 (94-97) & $93(91-95)$ \\
\hline & Mastectomy & $454(26.94)$ & $94(91-97)$ & $89(86-92)$ & $87(82-91)$ \\
\hline \multirow[t]{3}{*}{ Surgical margins } & Negative & $1104(65.52)$ & 98 (97-99) & 95 (93-97) & $94(91-96)$ \\
\hline & Positive & $244(14.48)$ & $100(97-101)$ & $98(94-100)$ & $95(89-98)$ \\
\hline & missing & $337(20.00)$ & $92(88-95)$ & $87(82-90)$ & $82(76-87)$ \\
\hline \multirow[t]{4}{*}{ Chemotherapy } & No & $817(48.49)$ & $98(97-100)$ & $96(94-98)$ & 95 (91-97) \\
\hline & Neoadjuvant & $180(10.68)$ & $95(90-97)$ & $87(81-92)$ & $83(76-88)$ \\
\hline & Adjuvant & $663(39.35)$ & $99(97-100)$ & $96(94-98)$ & $93(90-96)$ \\
\hline & Palliative & $25(1.48)$ & $40(21-59)$ & $16(5-33)$ & \\
\hline \multirow[t]{4}{*}{ Radiotherapy } & No & $334(22.45)$ & $95(92-98)$ & $91(87-95)$ & $88(81-93)$ \\
\hline & Neoadjuvant & $5(0.34)$ & $61(13-89)$ & $21(1-60)$ & \\
\hline & Adjuvant & $1128(75.81)$ & $100(99-100)$ & 97 (96-98) & 95 (93-97) \\
\hline & Palliative & $21(1.41)$ & $31(13-52)$ & $16(4-35)$ & \\
\hline \multirow[t]{4}{*}{ Immunotherapy } & No & $1498(88.90)$ & 98 (97-99) & $95(93-96)$ & $93(90-95)$ \\
\hline & Neoadjuvant & $27(1.60)$ & 90 (70-97) & $75(54-88)$ & $67(45-83)$ \\
\hline & Adjuvant & $144(8.55)$ & $98(94-100)$ & $95(89-98)$ & $92(85-97)$ \\
\hline & Palliative & $16(0.95)$ & $41(17-64)$ & $28(9-51)$ & \\
\hline \multirow[t]{4}{*}{ Endocrine therapy } & No & $662(39.29)$ & $94(91-96)$ & $90(87-92)$ & $86(82-90)$ \\
\hline & Neoadjuvant & $19(1.13)$ & $103(103-103)$ & $76(48-93)$ & $72(40-94)$ \\
\hline & Adjuvant & $985(58.46)$ & $100(99-101)$ & 98 (97-99) & 97 (94-99) \\
\hline & Palliative & $19(1.13)$ & $61(35-80)$ & $26(9-49)$ & \\
\hline
\end{tabular}

Table 4 First-line treatment and their association with survival

\begin{tabular}{|c|c|c|c|c|}
\hline Variable & Category & $N(\%)$ & Hazard ratio $(95 \% \mathrm{CI}) *$ & $p$ \\
\hline \multirow[t]{2}{*}{ Surgery } & Conservative & $1231(73.06)$ & 1 (ref) & \\
\hline & Mastectomy & $454(26.94)$ & 0.83 (0.56 to 1.22$)$ & 0.339 \\
\hline \multirow[t]{3}{*}{ Surgical margins } & Negative & $1104(65.52)$ & 1 (ref) & \\
\hline & Positive & $244(14.48)$ & $0.84(0.50$ to 1.42$)$ & 0.518 \\
\hline & Missing & $337(20.00)$ & $1.03(0.67$ to 1.56$)$ & 0.905 \\
\hline \multirow[t]{4}{*}{ Chemotherapy } & No & $817(48.49)$ & 1 (ref) & \\
\hline & Neoadjuvant & $180(10.68)$ & $1.18(0.72$ to 1.91$)$ & 0.514 \\
\hline & Adjuvant & $663(39.35)$ & $0.60(0.40$ to 0.89$)$ & 0.010 \\
\hline & Palliative & $25(1.48)$ & 8.44 (4.61 to 15.4$)$ & $<0.001$ \\
\hline \multirow[t]{4}{*}{ Radiotherapy } & No & $334(22.45)$ & 1 (ref) & \\
\hline & Neoadjuvant & $5(0.34)$ & $6.05(1.88$ to 19.5$)$ & 0.003 \\
\hline & Adjuvant & $1128(75.81)$ & $0.44(0.30$ to 0.65$)$ & $<0.001$ \\
\hline & Palliative & $21(1.41)$ & 5.31 (2.57 to 11.0$)$ & $<0.001$ \\
\hline \multirow[t]{4}{*}{ Immunotherapy } & No & $1498(88.90)$ & 1 (ref) & \\
\hline & Neoadjuvant & $27(1.60)$ & $1.79(0.87$ to 3.67$)$ & 0.113 \\
\hline & Adjuvant & $144(8.55)$ & $0.83(0.48$ to 1.44$)$ & 0.518 \\
\hline & Palliative & $16(0.95)$ & $5.22(2.57$ to 10.6$)$ & $<0.001$ \\
\hline \multirow[t]{4}{*}{ Endocrine therapy } & No & $662(39.29)$ & 1 (ref) & \\
\hline & Neoadjuvant & $19(1.13)$ & 1.17 (0.50 to 2.76$)$ & 0.719 \\
\hline & Adjuvant & $985(58.46)$ & $0.51(0.37$ to 0.71$)$ & $<0.001$ \\
\hline & Palliative & $19(1.13)$ & $2.18(1.05$ to 4.56$)$ & 0.037 \\
\hline
\end{tabular}

Hazard ratios and 95\% confidence intervals estimated via Weibull regression

*Hazard ratios adjusted for age, hospital, stage and grade 
between 1999 and 2005 [10], which reinforces TNM staging relevance for survival has not changed with recent treatment improvements, thus strengthening the importance of early diagnosis.

Recent developments, however, have focused on tumour biology, making the identification of breast cancer subtypes via differentiation grade or presence of hormonal and Her2/ neu receptors possible, heading to specific therapies according to tumour histological and molecular characteristics [6, 26-28]. Our results also confirmed higher survival for women with breast cancer positive to either oestrogen or progesterone receptors and negative to HER2 receptors, as well as worsening prognostic as grading increased from well to poorly differentiated tumour. In this regard, the new AJCC Pathological Prognostic Score [11] has been suggested by combining both anatomic staging and biological markers, thus refining the previous AJCC Anatomic Stage Groups [12], which is now intended only for regions were biological markers are not routinely available [11]. In our cohort, the AJCC Pathological Prognostic Score had large prognostic value with hazard ratios swiftly rising as the Pathological Prognostic Score increased. In addition, this score presents a higher predictive ability in premenopausal women. This can be explained by (i) the rate at which the cancer develops-tumours could be faster and receive poorer prognosis in premenopausal women-and (ii) the fact that a younger woman, i.e. premenopausal, with breast cancer is more likely to die because of the tumour itself, as opposed to postmenopausal women, who have more chances to die due to other causes. Of note, the analysis of Pathological Prognostic Score should have been restricted to women without neoadjuvant therapy as this score is based on the pathological TNM staging, which is obtained after surgery.

Adjuvant chemotherapy, radiotherapy or endocrine therapy was associated with better prognosis in our cohort, which agrees with previous reports [4, 29-31]. Neoadjuvant therapy, however, was associated with lower survival. Results on systemic therapy-survival relationship cannot be straight forwardly interpreted as, even after adjusting for stage and grade, there is still room for confounding by indication as women with more severe cancer are more likely treated with more aggressive therapies. For instance, neoadjuvant therapy is not usually recommended for low proliferating cancers and hormone receptor-positive, HER2negative, grading I-II cancers [26]; therefore, its high hazard ratios could be due to residual confounding as it is frequently indicated in cancers with worse prognostic.

Our study has some limitations. Firstly, the sample sizealthough enough for general results-is small for studying specific subgroups or interactions. Secondly, basal information was obtained from medical records, which could have partial information on some variables, leading to some amount of missing data. On this subject, it is noteworthy that missing categories did not follow a clear pattern in our results as missing data in TNM components behaved almost as the reference category (i.e. good prognostic), while missing data in grading performed as poorly differentiated tumours. Therefore, it is not possible for us to attribute any data omission in medical records to its irrelevance. Thirdly, our sample could be biased towards cancers with better prognostic as women with advanced disease could have refused to participate, thus underrepresenting women in stage IV; had this occurred, it could have overestimated relative survival; however, this problem should have not biased hazard ratios estimates. Finally, the multicentric design of our study is both a limitation and a strength. A limitation as routine clinical practice could vary from hospital to hospital, eventually increasing random variation; we dealt with this problem by adjusting all our analyses for hospital. Nevertheless, it is also a strength as it obtained a fair representation of usual clinical practice in Spain about 2008-2013. An additional strength is the active prospective follow-up, carried out via three complementary sources: medical records, phone calls to the patient and National Death Index consultation.

\section{Conclusions}

In conclusion, both TNM staging and histological/molecular biomarkers are associated with overall survival in Spanish women with breast cancer; when both are combined in the AJCC Pathological Prognostic Score, its prognostic value vastly improved in women without neoadjuvant therapy.

Acknowledgements The authors thank all patients and families for their participation in the MCC-Spain study, as well as all study centres and collaborators.

Author contributions Study conception and design: IG-A, TD-S and JL. Statistical analysis: IG-A, TD-S and JL. Coordination of substudy sites, recruitment and acquisition of data: IG-A, TD-S, CP, BP-G, PA, MG, AJM, LD, MF-O, VM, JA, GF-T, JI, RM-G, MD-S, MHA, JA-M, GC-V, AGP, EA, AM, NA, MK, MPM, JL. Drafting of the manuscript: IG-A, TD-S and JL. Contributions to the final version of the manuscript were made by all authors.

Funding Biological samples were stored at the biobanks supported by Instituto de Salud Carlos III- FEDER: Parc de Salut MAR Biobank (MARBiobanc) (RD09/0076/00036), 'Biobanco La Fe' (RD 09 0076/00021) and FISABIO Biobank (RD09 0076/00058), as well as at the Public Health Laboratory of Gipuzkoa, the Basque Biobank, the ICOBIOBANC (sponsored by the Catalan Institute of Oncology), the IUOPA Biobank of the University of Oviedo and the ISCIII Biobank. SNP genotyping services were provided by the Spanish 'Centro Nacional de Genotipado' (CEGEN-ISCIII). We thank all the subjects who participated in the study and all MCC-Spain collaborators. This work was supported by the 'Acción Transversal del Cancer', approved by the Spanish Ministry Council on the 11th October 2007, by the Instituto de Salud Carlos III, co-founded by FEDER funds - 'a way to build Europe' (grants PI08/1770, PI08/0533, PI08/1359, PI09/00773, PI09/01286, PI09/01903, PI09/02078, PI09/01662, PI11/01403, 
PI11/01889, PI11/00226, PI11/01810, PI11/02213, PI12/00488, PI12/00265, PI12/01270, PI12/00715, PI12/00150, PI14/01219, PI14/00613 and PI15/00069). Support was also provided by the Fundación Marqués de Valdecilla (grant API 10/09); the Junta de Castilla y León (grant LE22A10-2); the Consejería de Salud of the Junta de Andalucía (2009-S0143); the Conselleria de Sanitat of the Generalitat Valenciana (grant AP 061/10); the Recercaixa (grant 2010ACUP 00310); the Regional Government of the Basque Country; the Consejería de Sanidad de la Región de Murcia; European Commission grants FOOD-CT-2006-036224-HIWATE; the Spanish Association Against Cancer (AECC) Scientific Foundation; the Catalan Government DURSI (grant 2014SGR647); the Fundación Caja de Ahorros de Asturias; the University of Oviedo; Societat Catalana de Digestologia; and COST action BM1206 Eucolongene.

\section{Compliance with ethical standards}

Conflict of interest The authors declare that they have no conflict of interest.

Ethical approval All procedures performed in studies involving human participants were in accordance with the ethical standards of the institutional and/or national research committee and with the 1964 Helsinki declaration and its later amendments or comparable ethical standards.

Research involving human and animal rights This article does not contain any studies with animals performed by any of the authors.

Informed consent The protocol of MCC-Spain was approved by the Ethics committees of the participating institutions [16] At recruitment, all participants were informed about the study objectives and signed an informed consent, which also included the authorization for following up the patient via medical records or phone calls; only participants agreeing in being followed up were included in the inception cohorts. Confidentiality of data is secured by removing personal identifiers in the datasets. The database was registered in the Spanish Agency for Data Protection, number 2102672171. Permission to use the study database will be granted to researchers outside the study group after revision and approval of each request by the Steering Committee.

Open Access This article is licensed under a Creative Commons Attribution 4.0 International License, which permits use, sharing, adaptation, distribution and reproduction in any medium or format, as long as you give appropriate credit to the original author(s) and the source, provide a link to the Creative Commons licence, and indicate if changes were made. The images or other third party material in this article are included in the article's Creative Commons licence, unless indicated otherwise in a credit line to the material. If material is not included in the article's Creative Commons licence and your intended use is not permitted by statutory regulation or exceeds the permitted use, you will need to obtain permission directly from the copyright holder. To view a copy of this licence, visit http://creativecommons.org/licenses/by/4.0/.

\section{References}

1. Bray F, Ferlay J, Soerjomataram I et al (2018) Global cancer statistics 2018: GLOBOCAN estimates of incidence and mortality worldwide for 36 cancers in 185 countries. CA Cancer J Clin. https://doi.org/10.3322/caac.21492

2. Saadatmand S, Bretveld R, Siesling S, Tilanus-Linthorst MMA (2015) Influence of tumour stage at breast cancer detection on survival in modern times: population based study in 173797 patients. BMJ 351:h4901. https://doi.org/10.1136/bmj.h4901

3. Cancer today. https://gco.iarc.fr/today/home. Accessed $15 \mathrm{Apr}$ 2019

4. Clarke M, Collins R, Darby S, et al (2005) Effects of chemotherapy and hormonal therapy for early breast cancer on recurrence and 15-year survival: an overview of the randomised trials. Centre for Reviews and Dissemination (UK)

5. Guevara M, Burgui R, Díaz-González J et al (2017) Care patterns and changes in treatment for nonmetastatic breast cancer in 2013-2014 versus 2005: a population-based high-resolution study. Eur J Cancer Prev. https://doi.org/10.1097/CEJ.000000000000037 9

6. Goldhirsch A, Winer EP, Coates AS et al (2013) Personalizing the treatment of women with early breast cancer: highlights of the St gallen international expert consensus on the primary therapy of early breast cancer 2013. Ann Oncol Off J Eur Soc Med Oncol 24:2206-2223. https://doi.org/10.1093/annonc/ mdt 303

7. Chirlaque MD, Salmerón D, Galceran J et al (2018) Cancer survival in adult patients in Spain. results from nine populationbased cancer registries. Clin Transl Oncol 20:201-211. https:// doi.org/10.1007/s12094-017-1710-6

8. Sant M, Chirlaque Lopez MD, Agresti R et al (1990) (2015) Survival of women with cancers of breast and genital organs in Europe 1999-2007: results of the EUROCARE-5 study. Eur J Cancer Oxf Engl 51:2191-2205. https://doi.org/10.1016/j. ejca.2015.07.022

9. Allemani C, Weir HK, Carreira H et al (2015) Global surveillance of cancer survival 1995-2009: analysis of individual data for $25,676,887$ patients from 279 population-based registries in 67 countries (CONCORD-2). Lancet Lond Engl 385:977-1010. https://doi.org/10.1016/S0140-6736(14)62038-9

10. Saadatmand S, Bretveld R, Siesling S, Tilanus-Linthorst MMA (2015) Influence of tumour stage at breast cancer detection on survival in modern times: population based study in 173,797 patients. BMJ 351:h4901. https://doi.org/10.1136/bmj.h4901

11. Giuliano AE, Edge SB, Hortobagyi GN (2018) Eighth edition of the AJCC cancer staging manual: breast cancer. Ann Surg Oncol 25:1783-1785. https://doi.org/10.1245/s10434-018-6486-6

12. Lee SB, Sohn G, Kim J et al (2018) A retrospective prognostic evaluation analysis using the 8 th edition of the American joint committee on cancer staging system for breast cancer. Breast Cancer Res Treat 169:257-266. https://doi.org/10.1007/s1054 9-018-4682-5

13. Ibis K, Ozkurt S, Kucucuk S et al (2018) Comparison of Pathological Prognostic Stage and Anatomic Stage Groups According to the Updated Version of the American Joint Committee on Cancer (AJCC) breast cancer staging 8th edition. Med Sci Monit Int Med J Exp Clin Res 24:3637-3643. https://doi. org/10.12659/MSM.911022

14. Chirlaque MD, Salmerón D, Ardanaz E et al (2010) Cancer survival in Spain: estimate for nine major cancers. Ann Oncol 3:21-29. https://doi.org/10.1093/annonc/mdq082

15. WHO | ICD-10 online versions. In: WHO. https://www.who.int/ classifications/icd/icdonlineversions/en/. Accessed 9 Sep 2019

16. Castaño-Vinyals G, Aragonés N, Pérez-Gómez B et al (2015) Population-based multicase-control study in common tumors in Spain (MCC-Spain): rationale and study design. Gac Sanit 29:308-315. https://doi.org/10.1016/j.gaceta.2014.12.003

17. Alonso-Molero J, Molina AJ, Jiménez-Moleón JJ et al (2019) Cohort profile: the MCC-Spain follow-up on colorectal, breast and prostate cancers: study design and initial results. BMJ Open. https://doi.org/10.1136/bmjopen-2019-031904

18. Edge SB, Compton CC (2010) The American Joint Committee on Cancer: the 7th Edition of the AJCC Cancer Staging Manual 
and the Future of TNM. Ann Surg Oncol 17:1471-1474. https ://doi.org/10.1245/s10434-010-0985-4

19. Rakha EA, El-Sayed ME, Lee AHS et al (2008) Prognostic significance of Nottingham histologic grade in invasive breast carcinoma. J Clin Oncol Off J Am Soc Clin Oncol 26:3153-3158. https://doi.org/10.1200/JCO.2007.15.5986

20. Davis BW, Gelber RD, Goldhirsch A et al (1986) Prognostic significance of tumor grade in clinical trials of adjuvant therapy for breast cancer with axillary lymph node metastasis. Cancer $58: 2662-2670$

21. Navarro C (2006) The national death index: a largely expected advance in the access to mortality data. Gac Sanit 20:421-423

22. Dickman PW, Coviello E (2015) Estimating and modeling relative survival. Stata J 15:186-215. https://doi.org/10.1177/1536867X15 01500112

23. Colzani E, Liljegren A, Johansson ALV et al (2011) Prognosis of patients with breast cancer: causes of death and effects of time since diagnosis, age, and tumor characteristics. J Clin Oncol 29:4014-4021. https://doi.org/10.1200/JCO.2010.32.6462

24. Pestalozzi BC, Zahrieh D, Mallon E et al (2008) Distinct clinical and prognostic features of infiltrating lobular carcinoma of the breast: combined results of 15 international breast cancer study group clinical trials. J Clin Oncol 26:3006-3014. https://doi. org/10.1200/JCO.2007.14.9336

25. Dunnwald LK, Rossing MA, Li CI (2007) Hormone receptor status, tumor characteristics, and prognosis: a prospective cohort of breast cancer patients. Breast Cancer Res 9:R6. https://doi. org/10.1186/bcr1639
26. Gnant M, Harbeck N, Thomssen C (2011) St. Gallen 2011: summary of the consensus discussion. Breast Care 6:136-141. https ://doi.org/10.1159/000328054

27. Coates AS, Winer EP, Goldhirsch A et al (2015) Tailoring therapies-improving the management of early breast cancer: St. gallen international expert consensus on the primary therapy of early breast cancer 2015. Ann Oncol Off J Eur Soc Med Oncol 26:1533-1546. https://doi.org/10.1093/annonc/mdv221

28. Curigliano G, Burstein HJ, Winer EP et al (2017) De-escalating and escalating treatments for early-stage breast cancer: the St. gallen international expert consensus on the primary therapy of early breast cancer 2017. Ann Oncol 28:1700-1712. https://doi. org/10.1093/annonc/mdx308

29. Martinez FJ, Calverley PM, Goehring UM, Brose M, Fabbri LM, Rabe KF (2011) Effect of radiotherapy after breast-conserving surgery on 10-year recurrence and 15-year breast cancer death: meta-analysis of individual patient data for 10801 women in 17 randomised trials. Lancet 378:1707-1716. https://doi.org/10.1016/ S0140-6736(11)61629-2

30. Bergh J, Jönsson PE, Glimelius B et al (2001) A systematic overview of chemotherapy effects in breast cancer. Acta Oncol Stockh Swed 40:253-281

31. Corona SP, Roviello G, Strina C et al (2019) Efficacy of extended aromatase inhibitors for hormone-receptor-positive breast cancer: a literature-based meta-analysis of randomized trials. Breast Edinb Scotl 46:19-24. https://doi.org/10.1016/j.breast.2019.04.004

Publisher's Note Springer Nature remains neutral with regard to jurisdictional claims in published maps and institutional affiliations.

\section{Affiliations}

\section{Inés Gómez-Acebo ${ }^{1,2,25}$. Trinidad Dierssen-Sotos ${ }^{1,2}$. Camilo Palazuelos-Calderón ${ }^{2}$ • Beatriz Pérez-Gómez ${ }^{1,3}$. Pilar Amiano ${ }^{5}$. Marcela Guevara ${ }^{1,6,7}$. Antonio J. Molina ${ }^{8} \cdot$ Laia Domingo $^{9,10}$ - María Fernández-Ortiz ${ }^{2}$. Victor Moreno ${ }^{1,11,12,13}$. Juan Alguacil ${ }^{1,14}$. Guillermo Fernández-Tardón ${ }^{15}$. Josefa lbáñez ${ }^{16,17}$. Rafael Marcos-Gragera ${ }^{1,18,19}$ - Marian Diaz-Santos ${ }^{20} \cdot$ M. Henar Alonso ${ }^{1,11,12,13}$. Jessica Alonso-Molero ${ }^{2}$. Gemma Castaño-Vinyals ${ }^{1,21,22,23} \cdot$ Andrés García Palomo $^{24}$. Eva Ardanaz ${ }^{1,6,7}$. Amaia Molinuevo ${ }^{5}$ Nuria Aragonés ${ }^{1,4}$. Manolis Kogevinas ${ }^{1,21,22,23} \cdot$ Marina Pollán ${ }^{1,3} \cdot$ Javier Llorca ${ }^{1,2}$}

1 Consortium for Biomedical Research in Epidemiology and Public Health (CIBER Epidemiología y Salud Pública, CIBERESP), Madrid, Spain

2 University of Cantabria - IDIVAL, Santander, Spain

3 Cancer and Environmental Epidemiology Unit, National Center for Epidemiology, Carlos III Institute of Health, Madrid, Spain

4 Epidemiology Section, Department of Health, Public Health Division, Madrid, Spain

5 Public Health Division of Gipuzkoa, BioDonostia Research Institute, San Sebastian, Spain

6 Navarra Public Health Institute, Pamplona, Spain

7 IdiSNA, Navarra Institute for Health Research, Pamplona, Spain

8 Instituto de Biomedicina (IBIOMED), Universidad de León, León, Spain
9 Department of Epidemiology and Evaluation, IMIM (Hospital del Mar Medical Research Institute), Passeig Marítim, 25-29, 08003 Barcelona, Spain

10 Research Network On Health Services in Chronic Diseases (REDISSEC), Barcelona, Spain

11 Oncology Data Analytics Program, Hospitalet de Llobregat, Catalan Institute of Oncology (ICO), Barcelona, Spain

12 Colorectal Cancer Group, ONCOBELL Program, Bellvitge Biomedical Research Institute (IDIBELL), Hospitalet de Llobregat, Barcelona, Spain

13 Department of Clinical Sciences, Faculty of Medicine, University of Barcelona, Barcelona, Spain

14 Centro de Investigación en Recursos Naturales, Salud y Medio Ambiente (RENSMA), Universidad de Huelva, Huelva, Spain

15 Instituto de Investigación Sanitaria del Principado de Asturias-ISPA, UNIOVI and CIBERESP, Oviedo, Spain 
16 Cancer and Public Health Area, FISABIO - Public Health, Valencia, Spain

17 General Directorate of Public Health, Valencia, Valencian Community, Spain

18 Epidemiology Unit and Girona Cancer Registry. Oncology Coordination Plan, Department of Health, Autonomous Government of Catalonia, Catalan Institute of Oncology, Av. França, s/n, 17007 Girona, Spain

19 Descriptive Epidemiology, Genetics and Cancer Prevention Group, Biomedical Research Institute (IDIBGI),

C/ Dr. Castany, s/n, 17190 Salt, Spain
20 Centro de Investigación en Recursos Naturales, Salud y Medio Ambiente (RENSMA), Universidad de Huelva, Huelva, Spain

21 ISGlobal, Barcelona, Spain

22 IMIM (Hospital del Mar Medical Research Institute), Barcelona, Spain

23 Universitat Pompeu Fabra (UPF), Barcelona, Spain

24 Servicio de Oncología, Complejo Asistencial Universitario de León, León, Spain

25 Facultad de Medicina, Universidad de Cantabria, Avda. Herrera Oria s/n, 39011 Santander, Spain 